\title{
Influence of parameters of mixing of the mortar mixtures on the performance of ornamental composites for facade coating
}

\author{
Evgeniay Tkach $^{1^{*}}$, and Kanapiya Nurbaturov ${ }^{2}$ \\ ${ }^{1}$ Moscow state university of civil engineering, Yaroslavskoye shosse, 26, Moscow, Russia, 129337 \\ ${ }^{2}$ Limited Liability Partnership «INNOBUILD», Kazakhstan, Almaty, Auezov str., 84
}

\begin{abstract}
Studies have shown that the main physical-mechanical properties of decorative coatings based on colloidal cement systems greatly depend on the homogeneity of the structure of hardened stone, therefore, in the preparation of mortar mixtures were set the task of achieving this target. It is shown that vibrational mix of materials helps to ensure the preparation of mortar mixes with cement-based colloidal systems with a more homogeneous distribution of the components. The efficiency of vibrational mixing was determined by comparing the strength of the mortar mixes based on colloidal cement glue, cooked in vibromaster when the vibration acceleration with the strength of samples prepared in a standard mortar mixer of forced action without vibration. The results of the research confirmed some influence of the mineralogical composition of clinker the cement component of the colloidal material on the effect of vibration treatment solutions. Parameters preparation of the mortar mixtures based on cement colloidal material in a vibratory mixer. Optimum resonant operating frequency of the vibrations, at which is achieved the positive effect of mixing of the mixture is ensured with amplitude $5 \mathrm{~mm}$ while accelerating $214,8 \mathrm{~m} / \mathrm{S}^{2}$ and duration of mixing $60-90 \mathrm{~s}$. It is established that vibropressure contributes to the intensification hydration processes to temperature is minus $5{ }^{\circ} \mathrm{C}$
\end{abstract}

\section{Introduction.}

The construction of modern buildings requires the use of a huge variety of finishes, the main purpose of which is not only the architectural appearance but also protection of structures against aggressive external environments [1]. The development of decorative coatings based on technologies of deep processing of raw materials using construction waste, the regulation of surface phenomena in disperse systems, selection and optimization of compositions of composite materials based on colloidal cement materials.

Currently acute problem of disposal of construction waste, including concrete waste that is generated in the result of the destruction of residential buildings and concrete structures [2-4]. When designing cement-colloid composites with the use of concrete scrap special

\footnotetext{
* Corresponding author: ev_tkach@mail.ru
} 
attention is paid to the study of the influence of external factors on the processes of mixing and provision of operational properties of composites. Analysis of the research showed that improvement in processes of mixing of the mixture becomes possible only with the use of new effects, which are the vibration of the mixing device [5-7]. Therefore, to determine optimal conditions for a homogeneous distribution of the components of the mixture and obtain a homogeneous mixture it was investigated the influence of mixing on the basic properties of mortar mix.

\section{Problems.}

The goal of the presented research is set depending on the technological parameters of mixing particulate cement systems with the use of screenings from the concrete crushing to a uniform distribution of the components in the main mix volume, which ultimately determines the operational characteristics of decorative coatings for exterior designs. Studies have shown that the main physical-mechanical properties of decorative coatings based on colloidal cement systems greatly depend on the homogeneity of the structure of hardened stone, therefore, in the preparation of mortar mixtures were set the task of achieving this target. Studies have shown that when using conventional mixers for mortar mixes is dominated by processes that are not able fully to destroy agglomerates and do not provide the high homogeneity of the mixture. The analysis of previously performed studies have shown that a significant intensification of the processes of mixing can be achieved at the expense of vibration exposure [8-10]. The mobility characterizing properties such as viscosity, plasticity and uniformity of mortar mixture was determined by conventional stirring and mixing in a vibrating mixer. Water-cement ratio and mixing time of the mixtures was identical. The mobility of colloid-cement mortar was determined using the cylinder of Suttard the diameter of the spot spreading. Mixing of mortar mix produced with different amplitude (A) from 1; 3 to $5 \mathrm{~mm}$ and vibration frequency $(\omega)$ of $100 ; 150$ and 260 $\mathrm{s}^{-1}$. The mixing time was changed from 60,90 , and $120 \mathrm{~s}$. The determination of optimal parameters of mixing will allow us to achieve the ultimate uniformity of distribution of finely dispersed solid phase with optimal content in the dispersion medium in the initial stages of technology and stabilization of the achieved homogeneity and dispersion after completion of phase transformation, i.e. after the formation of the solid structure. The deceleration or acceleration of the processes of formation and hardening of an artificial stone largely dependent on temperature of curing and the method of preparation of the mixture. When evaluating the efficiency of mixing the colloid-cement mortar mix it is important to determine how the method of mixing intensificare the process of setting and hardening. It is important to assess the impact of vibration effects on structure formation of hardening of the stone and on the process of curing the colloid-cement mortars in terms of positive and negative temperatures. Hardening at lowered positive and small negative temperatures is accompanied by insufficient development of exothermic processes due to the fact that the hardening of the decorative coatings occurs in a thin layer. The authors found that lowering the temperature slows down the hydration process and, consequently, increase the strength [11-12], as in the period of setting of the binder of the concrete freezing of the most dangerous. To determine the effect of low temperatures on the strength of the samples obtained by vibropressure was prepared mortar mixture in the ratio 1:3, in water the ratio $\mathrm{W} / \mathrm{R}=0,35$. Samples were collected with no external defects, the average density of which did not differ from the minimum values by more than $50 \mathrm{~kg} / \mathrm{m}^{3}$. Samples after 4 hours storage in air was placed in the freezer and a drying Cabinet, where they maintain the required temperature. 


\section{Results}

These studies showed that the mobility of colloid-cement mortar mix that has been cooked in a conventional mortar mixer is much less than the mobility of the mixture is made in a vibrating mixer. Increase mobility in the vibrational mixing of the mixture was about $70 \%$. It is because vibropressure eliminates negative phenomena by reducing the viscosity of mortar mix, whereby the cement paste becomes more homogeneous in composition, plastic and adhesive than conventional mixing. The obtained results of the influence of the content of the clinker components of the cement $\left(\mathrm{C}_{3} \mathrm{~S}, \mathrm{C}_{2} \mathrm{~S}, \mathrm{C}_{3} \mathrm{~A}, \mathrm{C}_{4} \mathrm{AF}\right)$ included in the cement composition of the colloidal material, the effect of vibropressure colloidal cement mortar mix is shown in figure 1. On the radiograph of the sample of Portland cement LLP "Bukhtarma cement company" are clearly visible the peaks of the major minerals: $\mathrm{C}_{3} \mathrm{~S}(3,8660,3,0320,2,7754,2,1826,2,0519,1,6225), \mathrm{C}_{2} \mathrm{~S}(2,6062$, $1,7623,1,4870), \mathrm{C}_{3} \mathrm{~A}(2,8819,2,0519)$ and $\mathrm{C}_{4} \mathrm{AF}(7,3222,2,6463)$. In the sample of Portland cement LLP "Standardalert" clearly visible changes in the composition alyumoferritnoy phase $\mathrm{C}_{4} \mathrm{AF}(7,6094,2,6454)$ and the decrease in peak intensities of $\mathrm{C}_{3} \mathrm{~S}$ $(3.0318,2,7747,2,6070), \mathrm{C}_{2} \mathrm{~S}(1,7642,1,4868), \mathrm{C}_{3} \mathrm{~A}(2,8819,2,0519)$.
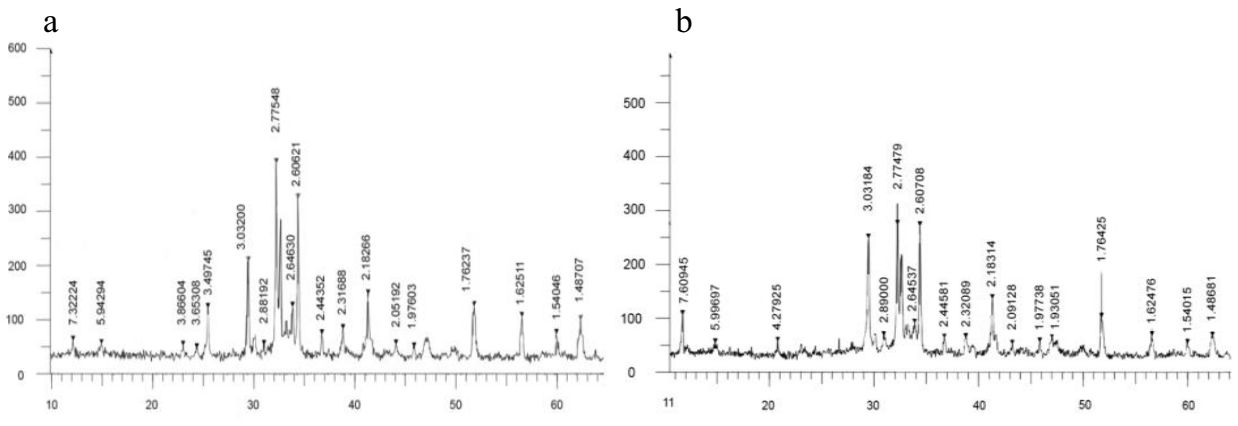

a - too "Bukhtarma cement company, b - too "Standardalert"

Fig. 1. Radiographs of ceramic components used in studies of Portland cement

The results are shown in table 1 (in the numerator of the filler of sand, in the denominator of screenings from the concrete crushing). Comparison of curing and mixing times allows to conclude the following: tensile strength of specimens in compression, cooked in vibromaster, in all periods of hardening higher than the corresponding values of the control samples prepared in the mortar mixer of forced action without vibration.

Table 1. The Influence of method and time of mixing of mortar on the basis of colloidal cement material and sand on the kinetics of curing

\begin{tabular}{|l|c|c|c|c|}
\hline \multirow{2}{*}{ Processing options } & \multicolumn{4}{|c|}{ The limit of compressive strength at the age, $\mathrm{MPa}$} \\
\cline { 2 - 5 } & 7 day & 14 day & 21 day & 28 day \\
\hline Mixing without vibrations & $33,8 / 32,4$ & $42,3 / 40,8$ & $45,6 / 43,6$ & $51,9 / 51,7$ \\
\hline Mixing in vibromaster for 60 s & $47,4 / 46,8$ & $50,2 / 49,6$ & $53,8 / 53,1$ & $58,7 / 58,2$ \\
\hline Mixing in vibromaster for 90 s & $50,0 / 49,6$ & $52,2 / 52,4$ & $54,7 / 54,3$ & $60,1 / 59,9$ \\
\hline
\end{tabular}

Laboratory tests showed that vibropressure shows a positive result, the process of hardening and the rate of strength development at different temperatures (table 2, in the numerator of the filler of sand, in the denominator of screenings from the concrete crushing). The results show that the effect of low temperatures, even for a short time negatively affects the process of curing 
Table 2. The Effect of mixing and curing on durability of mortar mixtures

\begin{tabular}{|l|c|c|c|}
\hline \multirow{2}{*}{$\begin{array}{c}\text { The } \begin{array}{c}\text { mixing of the } \\
\text { mixture } \\
\text { in mortar mixer }\end{array} \\
\text { Laboratory }\end{array}$} & \multirow{2}{*}{$\begin{array}{c}\text { The } \\
\text { temperature of } \\
\text { hardening, }\end{array}{ }^{0} \mathrm{C}$} & \multicolumn{2}{|c|}{$\begin{array}{c}\text { The tensile strength of the samples at the } \\
\text { age, } \mathrm{MPa}\end{array}$} \\
\cline { 3 - 4 } & \multirow{2}{*}{+30} & 1 day & 3 day \\
\hline Vibrating & \multirow{2}{*}{+20} & $27,6 / 28,0$ & $34,1 / 32,6$ \\
\hline Laboratory & \multirow{2}{*}{0} & $22,6 / 23,3$ & $32,5 / 31,4$ \\
\hline Vibrating & & $33,9 / 35,4$ & $47,7 / 47,9$ \\
\hline Laboratory & \multirow{2}{*}{$* 5$} & $2,4 / 2,2$ & $3,9 / 3,6$ \\
\hline Vibrating & & $1,2 / 1,1$ & $5,7 / 5,3$ \\
\hline Laboratory & & $1,6 / 1,5$ & $2,7 / 2,8$ \\
\hline Vibrating & & & $3,7 / 3,8$ \\
\hline
\end{tabular}

Hardening at low temperatures under the influence of early freezing due to the expansion of the mixing water slows down the hydration process, which negatively affects the formation of the structure of the stone, as freezing it will create a harmful amount of pores and channels that affect the strength characteristics of the material. However, the strength of samples obtained with the vibration stirring, it has an increase of strength compared to samples prepared in the laboratory mortar mixer to the age of 1 and 3 days and the curing temperature of $300 \mathrm{C}$, from 30 to $50 \%$. At a temperature of $200 \mathrm{C}$ curing - from 77 to $52 \%$. At a temperature of $00 \mathrm{C}$ hardening from 36 to $39 \%$. At the temperature of hardening minus $50 \mathrm{C}-33$ to $37 \%$. Small increase in strength during curing at low temperatures can be explained by the fact that after thawing tumors retain the porous structure of the stone, and the increase in strength does not occur. However, vibrational mixing is more effective in this case. Increased strength of the samples can be explained by the microstructure of the hardened stone, studied at 28 days age. The microstructure of the contact zone (figure 2) binder and fine aggregate in the samples, prepared in different ways.

a)

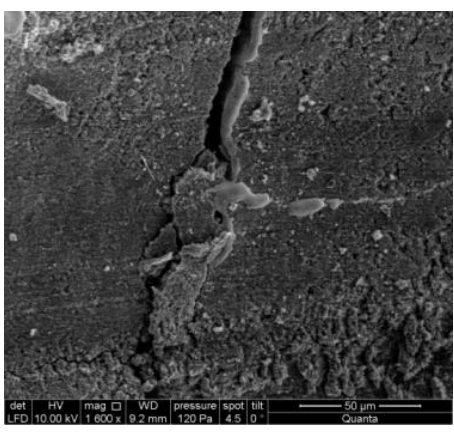

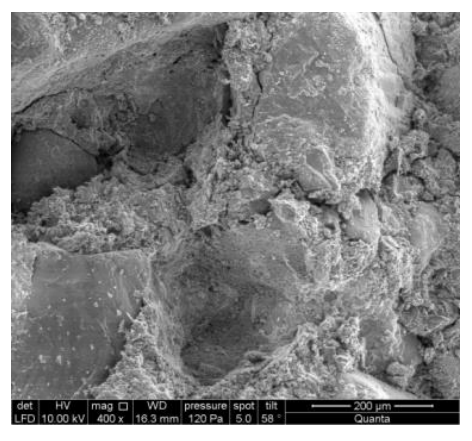


b)
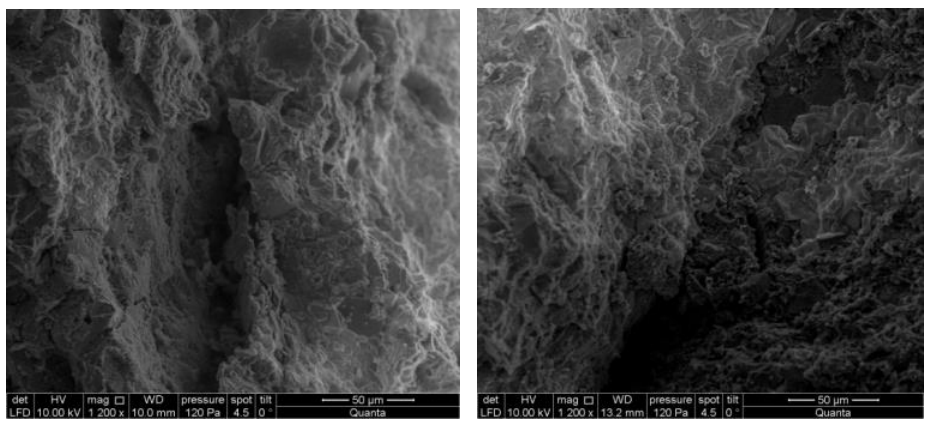

a) mixing without vibration; b) vibrational mixing

Fig. 2. The microstructure of the contact zone of binder and fine aggregate in the samples, prepared in different ways.

It is established that the strength characteristics of samples prepared in a vibratory mixer that harden at low and negative temperatures, comparable to the strength characteristics of the samples hardening at positive temperatures, which can be explained not only by high colloidal characteristics of cement composites modified with additives, but also mode mixing in vibratory mixer. The influence of vibratory impulses to the mixture improves the condition of the contact zone of sand with an astringent and also promotes the growth of tumors with improved composition and structure.

Table 3 presents comparative results of two methods of mixing, showing the dependence of the strength of mortar mix in different stages of hardening from the mixing equipment, the duration of the mixing ratio of the components of mortar mix.

Table 3. the dependence of the strength of mortar mix in different stages of hardening from the mixing equipment, the duration of the mixing ratio of the components of mortar mix

\begin{tabular}{|c|c|c|c|c|c|c|}
\hline \multirow{3}{*}{$\begin{array}{l}\text { The ratio of } \\
\text { mixture } \\
\text { components }\end{array}$} & \multirow{3}{*}{$\begin{array}{l}\text { Terms of } \\
\text { hardening, } \\
\text { day }\end{array}$} & \multirow{3}{*}{$\begin{array}{c}\text { Strength } \\
\text { specimens in } \\
\text { compression, } \\
\text { prepared in } \\
\text { laboratory } \\
\text { mixer, } \mathrm{MPa}\end{array}$} & \multicolumn{4}{|c|}{ The duration of mixing in vibromaster, $\mathrm{s}$} \\
\hline & & & 30 & 60 & 90 & 120 \\
\hline & & & $\begin{array}{l}\mathrm{R}_{\text {com }} \\
\mathrm{MPa}\end{array}$ & $\begin{array}{l}\mathrm{R}_{\text {com, }} \\
\mathrm{MPa}\end{array}$ & $\begin{array}{l}\mathrm{R}_{\text {com }} \\
\mathrm{MPa}\end{array}$ & $\begin{array}{l}\mathrm{R}_{\text {com }}, \\
\mathrm{MPa}\end{array}$ \\
\hline \multirow{4}{*}{$1: 1$} & 1 & 28,1 & 37,92 & 39,50 & 39,93 & 38,72 \\
\hline & 7 & 37,6 & 43,76 & 44,00 & 44,43 & 44,03 \\
\hline & 14 & 46,4 & 57,86 & 56,92 & 60,36 & 59,62 \\
\hline & 28 & 55,2 & 64,60 & 63,48 & 64,86 & 63,87 \\
\hline \multirow{4}{*}{$1: 2$} & 1 & 27,3 & 35,60 & 35,12 & 32,52 & 33,0 \\
\hline & 7 & 36,1 & 41,64 & 42,56 & 40,83 & 42,0 \\
\hline & 14 & 44,7 & 55,90 & 54,70 & 55,0 & 54,90 \\
\hline & 28 & 54,9 & 64,28 & 62,90 & 62,60 & 62,60 \\
\hline \multirow{4}{*}{$1: 3$} & 1 & 23,7 & 29,93 & 30,15 & 31,57 & 31,22 \\
\hline & 7 & 34,4 & 40,86 & 41,27 & 40,00 & 41,68 \\
\hline & 14 & 42,6 & 51,14 & 47,70 & 51,20 & 52,0 \\
\hline & 28 & 52,3 & 58,10 & 57,39 & 59,42 & 59,24 \\
\hline
\end{tabular}

The data obtained show that the preferred ratio of components (colloidal cement material: screenings from the concrete crushing) provided given a certain "viability" of a 
solution it is necessary to choose proceeding from conditions of the production technology of works and conditions of use decorative coatings. This is the most effective method in the implementation of technological schemes that reduce excessive activity or, on the contrary, increase it, depending on the working conditions of coverage by increasing or reducing the ratio of the components. With optimal quantities and optimal mixing ratio (1:3) the greatest increase of strength is observed at a mixing time of 60-90s.

The effect of the duration of vibropressure manifests itself not linear - it rises up in the first $60 \mathrm{~s}$, then stabiliziruemost $90 \mathrm{~s}$, and with the increase of time of vibropressure to $120 \mathrm{~s}$, a decrease in the resulting effect, which is manifested in lowering of strength of the samples in all periods of hardening. This is confirmed by data of other authors, who observed a pronounced effect [5]. In the study based on the efficiency of mixing sand and mortar mixes from exposure time, shown that prolonged exposure to vibration mixing leads to a decrease of the results achieved technological effect and the hardening effect of stone (increasing the strength), and the achievement of the effect depends on the vibration parameters and the ratio of the components.

Given sufficient experimental data, it is important to establish the most rational ratio of the components of the colloidal cement glue and sand it the best combined grading. Experimental data showed an increase in the proportion of colloidal material cement strength mortar per unit volume of solution is increased in all terms of hardening. The greatest increase of strength is observed in the first 7 day hardening components at a ratio of $1: 1$ (from 42 to $70.5 \%$ ) - in the duration of vibropressure from 30 to $120 \mathrm{C}$. The most effective is a ratio of 1:3 (cement colloidal material : screenings from the concrete crushing), in which due to a sufficient concentration of particles of colloidal cement glue in the matrix created conditions favorable for the formation of the stone structure of low voltage intergrowths of crystals. It should take into account the fact that the increase in the content of screenings from the concrete crushing instead of natural sand in the mortar mix helps to reduce the development of deformation shrinkage, reduce the risk of spreading of shrinkage cracks and failure of the coating, and to reduce the share of the binder and therefore of cement, which is a priority for improving economic efficiency.

\section{Conclusions and recommendations}

Optimal vibration intensity and duration of mixing components of the mortar mixture based on cement colloidal materials contributes to obtaining a high uniformity of distribution of different phases. Determined that the optimum resonant operating frequency of the vibrations, at which is achieved the positive effect mixing of the mixture is provided with a vibration amplitude of $5 \mathrm{~mm}$, when accelerating $214,8 \mathrm{~m} / \mathrm{S}^{2}$. The duration of stirring the mixture, necessary for obtaining adequate technological effect depends on the amount of kneading and 60-90 C. It is shown that vibrational mix of materials helps to ensure the preparation of colloidal mortar of higher quality by the degree of homogeneity. Vibratory mixing of mortar mixes with different particle size and density of components achieved greater homogenization, unattainable in the traditional way of mixing.

Confirmed a significant influence of the mineralogical composition of the clinker component of the colloidal cement glue on the effect of vibration treatment solutions. The difference in mineralogical composition affected the quantitative and qualitative effect. With the increase of tricalcium silicate and tricalcium aluminate in the cement clinker mixing efficiency is significantly increased.

It is established that vibropressure provides intense hydration, faster structure formation and, correspondingly, the growing strength of the mortar mixtures to a temperature of minus $50{ }^{\circ} \mathrm{C}$. This can be explained by the dense structure of the hardened stone and more homogeneous structure of the tumors. Thus, the executed researches have allowed to 
establish the technological parameters of mixing particulate cement systems with the use of screenings from the concrete crushing with uniform distribution of components in the main volume with improved performance decorative composites for facade coatings.

\section{References}

1. Oreshkin D. V. Problems of building materials and production of building materials // Building materials. 2010. No. 11. p. 6-9.

2. Pakhratdinov A. A., Tkach E. V., Oreshkin D. V. Environmental and geo-Environmental rationale for recycling concrete waste as crushed stone in the production of concrete products// Ecology of urbanized areas. - 2016. - No. 3. - p. 84-88.

3. Bezgodov I. M., Fahrutdinov A. A., Tkach E. V. Physical and mechanical characteristics of concrete as crushed stone recycled crushed concrete // Vestnik MGSU. - Moscow, 2016. No. 10 - p. 24-35.

4. Bazhenov Yu. M., S. Murtazaev, A. Y. Efficient concretes and mortars for construction and rehabilitation of roads using concrete scrap and dump ashes in thermal power plants // Vestnik MGSU.- 2008.- No. 3. - p. 124-128.

5. Barantseva, E. A., Mizonov V. E., Khokhlova Yu. V. Processes of mixing of granular materials: modeling, optimization, design // GOUVPO "the Ivanovo state power University. V. I. Lenin". - Ivanovo, 2008. -p.116.

6. Bazhenov, Y. M., Chernyshov E. M., Korotkikh D. N. Design of modern concrete structures: defining principles and technological platforms //Building materials. 2014. No. 3. p. 6-14.

7. Boldyrev A. A., Romanov I. V., Voronin V. V., Alimov L. A study of the formation of structure and properties of multi-component concrete // Scientific review. 2013. No. 9. -p. 177-181.

8. Uriev N. B. Modelling of the structural and mechanical characteristics of disperse systems under dynamic effects//Colloid journal. 2013. T. 75. No. 5. -p. 596.

9. Ruzhyn S. I. Influence of chemical characteristics of cement on the effectiveness of vibroactivity. Site access: /http://www.ibeton.ru/a158.php.

10. Duval R., Kadri E. H. Influence of silica fume on the workability and the compressive strength of high-performance concretes //Cem. and concr stock. Res. - 1998. - Vol.28. - No. 4. - p. 533547.

11. Stark. The hydration of cement and microstructure of concrete // Cement and its application. 2011. - No. 2.- p. 90-94.

12. Serdyukov A. A. Rakhimbaev S. M. Influence of negative temperatures on the hardening of the concrete // concrete and reinforced Concrete. -2013. - №1(18). -p. 52-54. 